\title{
IS THE TONGUE AN “ALTERNATIVE DONOR SITE FOR ANTERIOR URETHROPLASTY”?
}

\author{
MD. ASADUZZAMAN ${ }^{1}$, MD. WALIUL ISLAM ${ }^{1}$, MD. NURUL HOODA ${ }^{1}$, TOHID MD. SAIFUL HOSSAIN ${ }^{2}$, MD. \\ SHARIFUL ISLAM ${ }^{3}$, MD. ABDUS SALAM ${ }^{3}$, ENAMUL RASHID ${ }^{3}$, AKMZI BHUIYAN ${ }^{1}$, ABU BAKAR SIDDIQUE ${ }^{1}$
}

${ }^{1}$ Department of Urology, National Institute of Kidney Diseases and Urology, Dhaka, ${ }^{2}$ Department of Urology, Bangabagabandhu Sheikh Mujib Medial University, Dhaka

\begin{abstract}
Absitact
Objective: To evaluate the effectiveness of a lingual mucosal graft (LMG) urethroplasty for long segment (>2cm) anterior urethral strictures.

Materials and Methods: A total of 30 patients underwent urethroplasty for anterior urethral strictures using dorsal onlay of a LMG from January 2009 to December 2010. We selected 21 to 56 years old (mean age 36.6). Stricture length was 22 to $59 \mathrm{~mm}$ (mean 36); 14 strictures were in the bulbar urethra, 09 were in the proximal penile and 07 were in both bulbar and penile urethra. Postoperatively all patients were followed with urethrography, uroflowmetry, cystourethrography and urethroscopy after 3 weeks, 3 months and 06 months. Successful reconstruction criteria were peak flow rate greater than $15 \mathrm{ml}$ per second and no need for postoperative urethral dilation.
\end{abstract}

Results: The mean period of follow-up was 9 months (range 4-12). The overall success rate at $3^{\text {rd }}$ week and $3^{\text {rd }}$ month was $96.7 \%$ and at 6 th month was $90 \%$. Three patients developed repeat stricture at the anastomotic site. All the patients were able to resume oral fluid within $24 \mathrm{~h}$, eat soft solid diet in 48-72 $h$ and return to normal diet after 4- 5 days of surgery. No patient suffered from difficulty in opening the mouth, salivation disturbances, or difficulty in protrusion of tongue.

Conclusions: $L M G$ is easy to harvest. $L M G$ seems to be associated with less postoperative pain and a minor risk of donor site complications or without any functional or esthetic deficiency. The tongue may be the best alternative donor site.

Keywards: Lingual mucosa; Urethral stricture; Urethroplasty.

Bangladesh J. Urol. 2012; 15(1): 11-14

\section{Introduction}

The urethral stricture is fibrotic narrowing of urethral lumen and fibrosis usually extends into the surrounding corpus spongiosum causing spongiofibrosis ${ }^{1}$. Anterior urethral strictures are common in routine urological practice. There is a wide variety of options for managing anterior urethral strictures starting from urethral dilatation to substitution urethroplasty for long strictures. Since the 1990s, a large variety of free extragenital graft tissues have been used for urethroplasty, such as the ureter, saphenous vein, appendix, full-thickness skin, bladder mucosa, and buccal mucosa ${ }^{2}$. Currently, buccal mucosal graft (BMG) provides excellent clinical results but may also cause oral complications ${ }^{3-7}$. The first use

Correspondence: M Asaduzzaman, Department of Urology, National Institute of Kidney Diseases and Urology, Dhaka, E-mail: asadnikdu@gmail.com of tongue tissue as an alternative donor site in graft urethroplasty ${ }^{8}$. Lingual mucosa has constant availability, easy harvesting, and favorable immunologic properties (resistance to infection) and tissue characteristics i.e, a thick epithelium, high content of elastic fibers, thin lamina propria, and rich vascularization, and it is not hairy ${ }^{9}$. The use of lingual mucosal graft (LMG) for the anterior urethroplasty is well tolerated and effective in patients with anterior urethral strictures requiring surgery. In our study, we describe our initial experience with Lingual mucosal graft (LMG) urethroplasty for repairing long anterior urethral strictures.

\section{Materials and Methods}

Quasi Experimental study was conducted in the department of urology, National Institute of Kidney Diseases \& Urology, Dhaka. From January 2009 to 
December 2010, we selected 30 men 21 to 56 years old (mean age 36.6 ) for single stage dorsal onlay urethroplasty with LMG. Stricture length was 22 to 59 $\mathrm{mm}$ (mean 36), 14 strictures were in the bulbar urethra, 09 were in the proximal penile and 07 were in both bulber and penile urethra. All patients were evaluated preoperatively with uroflowmetry, urethroscopy and retrograde and voiding urethrography.

Surgical technique: The surgical procedure is performed with the patient under general anesthesia with endotracheal intubation. A midline perineal incision was made. The stricture segment was identified, dissected and completely mobilized from corpora cavernosa. It was then rotated 180 degree and an incision was made on the stricture segment dorsally at midline and extended proximally and distally for $0.5 \mathrm{~cm}$ into the healthy urethra ${ }^{10,11}$ and the length of the urethrotomy is measured to harvest an adequate free graft.

\section{Harvesting and preparation lingual mucosal graft:}

All cases were performed by a team of urologists. A standard mouth opener was put into place. The apex of the tongue was passed through via a stitch for traction outside of the mouth to expose the ventrolateral surface of the tongue. Grafts were harvested from the ventral to lateral mucosal lining of the tongue. The required graft was measured. The graft was harvested unilaterally from the tongue, if large graft required then harvested bilaterally from the tongue. The harvest graft site was infiltrated with a mixed solution of $1 \%$ lignocaine with $1: 100000$ adrenaline. The graft edges were incised and a fullthickness mucosal graft was harvested using a sharp knife beginning at the anterior landmark of the graft. The donor site bed was carefully examined for bleeding and the donor site was closed using 4-0 polyglactin running sutures. Graft defatting was performed until all underlying fibrovascular tissue was completely removed ${ }^{12}$.
Urethroplasty: The technique of urethroplasty is dorsal onlay lingual mucosal graft urethroplasty. Opposite the dorsal urethrotomy performed earlier, the graft was fixed over the corpora cavernosa in the midline with intermittent 5-0 polyglactin suture. Next, it was coapted to the urethral epithelium in a tension-free manner with the help of 5-0 polyglactin sutures in a running continuous manner over a $14 \mathrm{~F}$ bi-channel Foley catheter.

\section{Postoperative Management and Follow-up:}

All the patients were followed up with pericatheter urethrography after 3 weeks and uroflowmetry, retrograde urethrography, and micturating cystourethrography after 3 and 6 months. The follow-up thereafter was determined by the symptoms and included a flow rate study. Urethrography was only repeated if symptoms developed or a deteriorating flow rate suggested recurrent stricture. The catheter was removed if no extravasation of contrast occurred on the pericatheter urethrography. If extravasation was present, the catheter was kept in place for another week.

Drain removed on 1st postoperative day. Dressing removed on 3rd postoperative day. When recovery was uneventful, patient was discharged after 7-8 postoperative day. All patients were followed up at 3rd week, 3rd month and 6th month after surgery

\section{Evaluation}

Success was defined as a patient having normal voiding; urine flow rate on uroflowmetry is ${ }^{3} 15 \mathrm{ml} / \mathrm{sec}$ and no recurrent stricture on urethrogram and urethrocystoscopy.

\section{Results and Observation}

A total of 30 patients with anterior urethral stricture included in this study according to the selection criteria. Therefore, a total of 30 patients were included for final calculation. On the basis of results of uroflowmetry done at 3 rd week, after removal of penile catheter and repeat

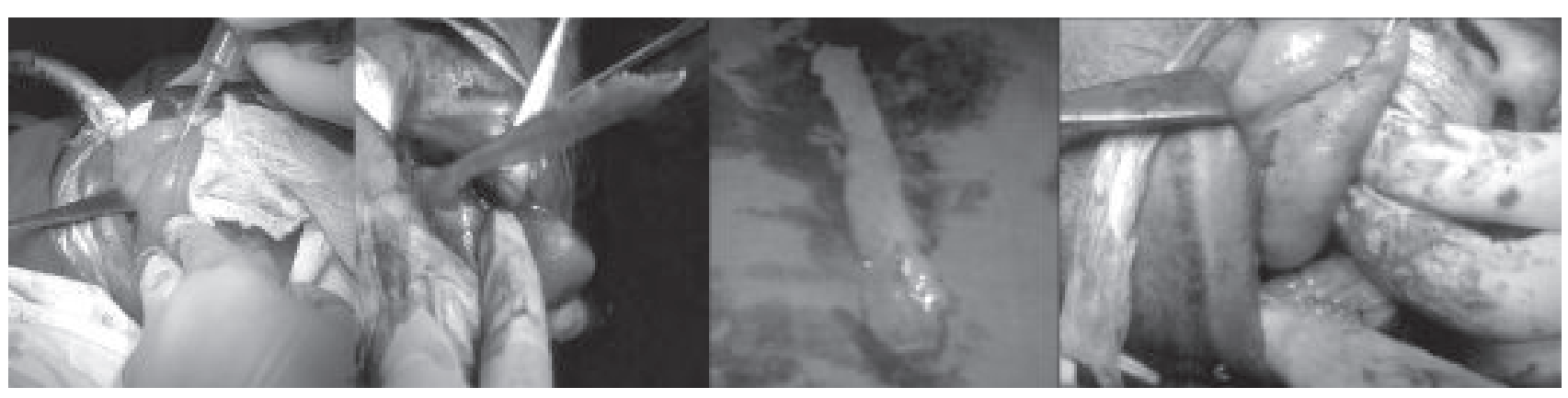

Fig.-1 : 


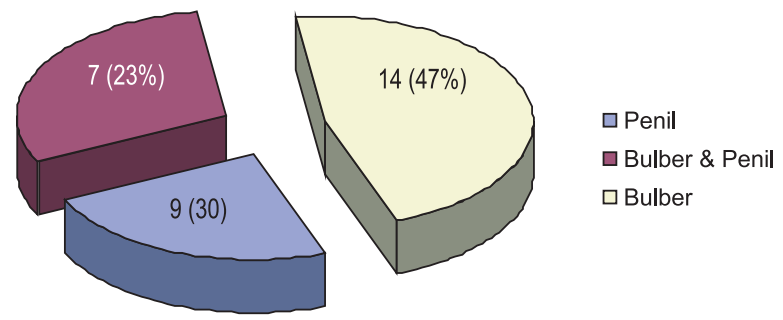

Fig.-2 :

at $3^{\text {rd }}$ and 6 th month success rate were $96.7 \%, 96.7 \%$ and $90.0 \%$ respectively. In RGU and MCU, at 3rd month follow up stricture was found in 01 case and normal caliber urethra was found in 29 cases, revealed success rate of $96.7 \%$ and at 6 th month follow up stricture was found in 3 cases and normal caliber urethra was found in 27 cases, revealed success rate of $90.0 \%$. During urethrocystoscopy at 6th month stricture was found in 3 cases and normal caliber urethra was found 27 cases, revealed success rate of $90.0 \%$. All the patients were able to resume oral fluid within $24 \mathrm{~h}$, eat soft solid diet in 48-72 $\mathrm{h}$ and return to normal diet after 4-5 days of surgery. No patient suffered from difficulty in opening the mouth, salivation disturbances, or difficulty in protrusion of tongue.

Follow up

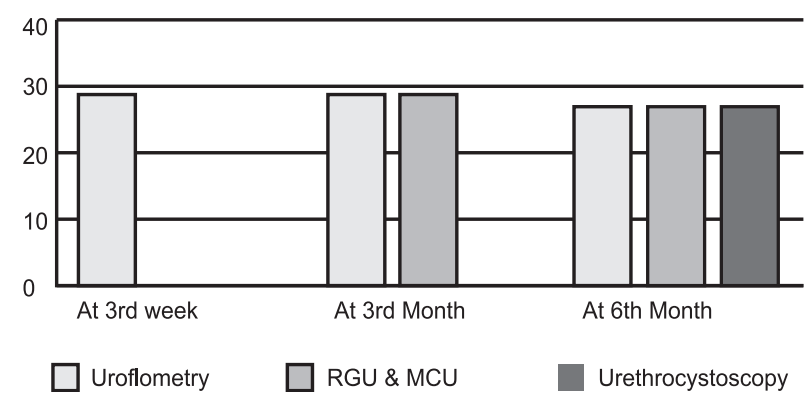

Fig.-3 :

In response to a question whether patients would have his lingual mucosa harvested again if require, $83.3 \%$ were satisfied, $10.0 \%$ no and $6.7 \%$ had mixed feelings. Overall success rate was $90.0 \%$.

\section{Discussion}

Open urethroplasty is regarded as the gold standard treatment for urethral strictures. The ideal surgical technique for substitution urethroplasty should be simple, safe, reliable and reproducible in the hands of any surgeon.
Substitution urethroplasty is the mainstay of the management for long anterior urethral strictures. Though BMG is the gold standard, at present studies have been published using LMG with equal efficacy but less donor site morbidity.

Simonato et al. first described the use of tongue tissue as an alternative donor site in graft urethroplasty ${ }^{8}$. Barbagli et al. showed the use of lingual mucosal graft for the anterior urethroplasty is well tolerated and effective in patients with urethral strictures requiring surgery ${ }^{13}$.

The mucosa covering the ventrolateral aspect of the tongue is identical in structure with that lining the rest of the oral cavity8,13-15. Kumar et al. discussed as with buccal mucosa, lingual mucosa has constant availability, easy harvesting, and favorable immunologic properties (resistance to infection) and tissue characteristics i.e, a thick epithelium, high content of elastic fibers, thin lamina propria, and rich vascularization, and it is not hairy ${ }^{9}$.

Mean stricture length $36.03 \mathrm{~mm}(22-54 \mathrm{~mm})$ in the present study. Barbagli et al. and Kumar et al. showed mean stricture length $4.5 \mathrm{~cm}(4-6 \mathrm{~cm})$ and $4.2 \mathrm{~cm}(3-10$ $\mathrm{cm}$ ) for lingual mucosal graft, respectively $\mathrm{y}^{9,13}$.

Uroflowmetry showed Q-max varied from 3.5 to $8 \mathrm{ml} /$ $\mathrm{sec}$ in this series preoperatively. Postoperatively at 3rd week after removal of urethral catheter and at 3rd month $29(96.7 \%)$ patients had Q-max e" $15 \mathrm{ml} / \mathrm{sec}$ and at 6 th month 27 (90.0\%) patients had Qmax e" $15 \mathrm{ml} / \mathrm{sec}$. In lingual mucosal graft urethroplasty. Simonato et al. showed at peak flow rate improved from 6 (4 to 8.9) $\mathrm{ml}$ to 34.3 (19.1 to 64.1$) \mathrm{ml} / \mathrm{sec}$ by uroflowmetry and success rate $87.5 \%$ ( 7 of 8 ), at $3^{\text {rd }}$ month follow up and at 12 th month follow up peak flow rate was 24 (16.3 to $30.4) \mathrm{ml} / \mathrm{sec}$ and success rate $80 \%(4 \text { of } 5)^{8}$. Barbagli et al. showed $90 \%$ (9 10) success rate of LMG and average follow up 5 month ( 3 to 12 month) ${ }^{13}$. Das et al. showed in LMG peak flow rate $35.5 \mathrm{ml} / \mathrm{sec}$ and 25.06 $\mathrm{ml} / \mathrm{sec} 3$ and 6 month follow-up, respectively and success rate was $83.3 \%{ }^{17}$.

During follow up at 3rd month RGU and MCU revealed stricture in 1 (3.3\%) patient. Success rate was $96.7 \%$. During follow up at 6 th month, RGU and MCU revealed stricture in $3(10.0 \%)$ patients. Success rate was $90.0 \%$. This is comparable with Simonato et al. who showed $81.8-100 \%$ success after $\mathrm{LMG}^{18}$.

In this series during urethrocystoscopy at 6th month stricture was found in $3(10.0 \%)$ cases. Success rate $90.0 \%$. Simonato et al. and Das et al. reported $12.5 \%$ 
Is the Tongue an "Alternative Donor Site for Anterior Urethroplasty"?

and $16.7 \%$ recurrent stricture of lingual mucosal graft urethroplasty for anterior urethral stricture which is comparable to this study 8,17 .

In the present study the overall success rate of lingual mucosal graft urethroplasty was $90.0 \%$. Overall success of lingual mucosal graft patch urethroplasty was similar to other studies, Simonato et al., Das et al., Singh et al. and Barbagli et al., also reported success rate were $87.5 \%, 83.3 \%, 90 \%$, respectively $8,13,14,17$.

In this study it was observed that the mucosa of the tongue, which is identical to the mucosa of the rest of the oral cavity, is a safe and effective graft material in the armamentarium for urethral reconstruction with potential minor risks of donor site complications.

\section{Conclusion}

In our experience, the mucosa of the tongue, which is identical to the mucosa of the rest of the oral cavity, is a safe and effective graft material for urethral reconstruction with a minor risk of donor site complications. Future comparative studies will be necessary to compare the results with BMG. Our initial results are encouraging but additional work and a strict follow-up are necessary to compare the outcomes with other graft materials and to make final conclusions.

Conflict of Interest : None declared

\section{References}

1. McAninch JW. Disorders of the penis and male urethra. In: Tanaqo EA and McAninch JW (17th ed.). Smith's general urology. Philadelphia, New York: McGraw-Hill, 2000; 625-637.

2. Dessanti A, Rigamonti W and Merulla V. Autologous buccal mucosa graft for hypospadias repair: An initial report. J Urol1992; 147: 1081-1084.

3. Andrich DE and Mundy AR. Substitution urethroplasty with buccal mucosal free grafts. J Urol 2001; 165: 1131.

4. Wessells $\mathrm{H}$. Ventral onlay graft techniques for urethroplasty. Urol Clin North Am. 2001;29:381.

5. Heinke T, Gerharz EW, Bonfig R and Riedmiller H. Ventral onlay urethroplasty using buccal mucosa for complex stricture repair. Urology 2003; 61: 1004.

6. Pansadoro V, Emiliozzi P, Gaffi M, Scarpone P, DePaula $F$ and Pizzo M. Buccal mucosa urethroplasty in the treatment of bulbar urethral strictures. Urology 2003; 61: 1008.
7. Dublin N and Stewart LH. Oral complications after buccal mucosal graft harvest for urethroplasty. BJU Int 2004; 94: 867.

8. Simonato A, Gregori A, Lissiani A, Galli S, Ottaviani $\mathrm{F}$, Rossi $R$ et al. The tongue as an alternative donor site for graft urethroplasty: a pilot study. J Urol 2006; 175 : 589-92.

9. Kumar A, Goyal NK, Das SK, Trivedi S, Dwivedi US and Singh PB. Oral complications after lingual mucosal graft harvest for urethroplasty. ANZ J. Surg 2007; 77: 970-973.

10. Barbagli G. Dorsal free graft urethroplasty. J Urol 1996; 155: 123-6.

11. Iselin CE, Webster GD. Dorsal onlay graft urethroplasty for repair of urethral stricture. J Urol 1999;161:815-8.

12. Xu YM, Qiang FU, Ying-long SA, Zhang J, Jin CR, Jie-min SI and Song LJ. Treatment of urethral strictures using lingual mucosa urethroplasty: experience of 92 cases. Chin Med J 2010;123: 458-462.

13. Barbagli G, De Angelis M, Romano G, Ciabatti PG and Lazzeri $M$. The use of lingual mucosal graft in adult anterior urethroplasty: surgical steps and short-term outcome. Eur Urol 2008;54:671-6.

14. Singh PB, Das SK, Kumar A, Sharma GK, Pandey $A K$, Swain $S$ et al. Dorsal onlay lingual mucosal graft urethroplasty: Comparison of two techniques, International Journal of Urology 2008;15: 1002-1005.

15. Guerrerosantos J, Dicksheet S and Ruiz-RazuraAF. Tongue composite graft for correction of a vermilion defect. Plast Reconstr Surg 1985;76:451-454.

16. Kumar A, Das SK, Sharma GK, Pandey AK, Trivedi $S$, Dwivedi US et al. Lingual mucosal graft urethroplasty for anterior urethral strictures: Our technique of graft harvesting. World J Urol 2008; 26: $275-80$.

17. Das SK, Kumar A, Sharma GK, PandeyAK, Bansal $H$, Trivedi S, Dwivedi US et al. Lingual mucosal graft urethroplasty for anterior urethral strictures. Urology 2009; 73:105-108.

18. Simonato A, Gregori A, Ambruosi C, Venzano F, Varca V, Romagnoli A et al. Lingual mucosal graft urethroplasty for anterior urethral reconstruction. Eur Urol 2008; 54: 79-87.

\section{Abbreviations}

LMG : Ligual Mucosal graft

MCU : Micturating Urethrogram

RGU : Retrograde Urethrogram 